Tuberc Respir Dis 2013;74:207-214

Copyright(C)2013. The Korean Academy of Tuberculosis and Respiratory Diseases. All rights reserved.

\title{
Usefulness of Plasma Procalcitonin to Predict Severity in Elderly Patients with Community-Acquired Pneumonia
}

Ji Hye Kim, M.D. ${ }^{1}$, Joo Wan Seo, M.D. ${ }^{1}$, Jeong Ha Mok, M.D. ${ }^{1}$, Mi Hyun Kim, M.D. ${ }^{1}$, Woo Hyun Cho, M.D. ${ }^{1}$, Kwangha Lee, M.D., Ph.D. , Ki Uk Kim, M.D., Ph.D. ${ }^{1}$, Doosoo Jeon, M.D., Ph.D. , Hye-Kyung Park, M.D., Ph.D. ${ }^{1}$, Yun Seong Kim, M.D., Ph.D. ${ }^{1}$, Hyung Hoi Kim, M.D., Ph.D. ${ }^{2}$, Min Ki Lee, M.D., Ph.D. ${ }^{1}$

Departments of ${ }^{1}$ Internal Medicine and ${ }^{2}$ Laboratory Medicine, Pusan National University School of Medicine, Busan, Korea

Background: Community-acquired pneumonia (CAP) is one of the leading causes of death among the elderly. Several studies have reported the clinical usefulness of serum procalcitonin, a biomarker of bacterial infection. However, the association between the levels of procalcitonin and the severity in the elderly with CAP has not yet been reported. The aim of this study was to evaluate usefulness of procalcitonin as a predictor of severity and mortality in the elderly with CAP.

Methods: This study covers 155 CAP cases admitted to Pusan National University Hospital between January 2010 and December 2010. Patients were divided into two groups ( $\geq 65$ years, $n=99$; $<65$ years, $n=56$ ) and were measured for procalcitonin, C-reactive protein (CRP), white blood cell, confusion, uremia, respiratory rate, blood pressure, 65 years or older (CURB-65) and pneumonia severity of index (PSI).

Results: The levels of procalcitonin were significantly correlated with the CURB-65, PSI in totals. Especially stronger correlation was observed between the levels of procalcitonin and CURB-65 in the elderly (procalcitonin and CURB-65, $\rho=0.408$ with $\mathrm{p}<0.001$; procalcitonin and PSI, $\rho=0.293$ with $\mathrm{p}=0.003$; procalcitonin and mortality, $\rho$ $=0.229$ with $\mathrm{p}=0.023$ ). The correlation between the levels of CRP or WBC and CAP severity was low. The existing cut-off value of procalcitonin was correlated with mortality rate, however, it was not correlated with mortality within the elderly.

Conclusion: The levels of procalcitonin are more useful than the levels of CRP or WBC to predict the severity of CAP. However, there was no association between the levels of procalcitonin and mortality in the elderly.

Key Words: Community-Acquired Infections; Aged; Pneumonia; Procalcitonin

\section{Introduction}

Pneumonia is the sixth leading cause of overall mortality in Republic of Korea in 2011, which represents a 15.3\% increase from 2010 and a 186.2\% from $2001^{1}$. Pneumonia in older people refers to pneumonia in peo-

Address for correspondence: Min Ki Lee, M.D., Ph.D. Department of Internal Medicine, Pusan National University Hospital, Pusan National University School of Medicine, 179 Gudeok-ro, Seo-gu, Busan 602-739, Korea

Phone: 82-51-240-7225, Fax: 82-51-244-8180

E-mail: leemk@pusan.ac.kr

Received: Sep. 16, 2012

Revised: Oct. 18, 2012

Accepted: Mar. 21, 2013

(a) It is identical to the Creative Commons Attribution Non-Commercial License (http://creativecommons. org/licenses/by-nc/3.0/). ple aged 65 or older. Pneumonia is one of the most common diseases, leading to death among the elderly. Older people tend to develop different symptoms of pneumonia, when compared with young people, making it difficult for doctors to treat and predict the prognosis. Instead of typical respiratory symptoms such as fever, cough and sputum, older people may have more vague signs such as subtle changes in mental status $^{2}$. Older adults have the risk for delayed diagnosis for pneumonia. Older patients are at the high risk of developing concurrent illness, which affect clinical outcome even after treatment ${ }^{3}$.

Generally, a severity-based approach is recommended for the diagnosis and treatment of community-acquired pneumonia. Pneumonia severity index (PSI) and 
CURB-65 are widely used as severity scoring systems. And severity scores serve as useful indicators in clinical decision making ${ }^{4}$. PSI, developed by Fine et al. ${ }^{5}$ is measured with 20 items, and each item is scored. In PSI, patients are classified into five severity classes where the higher class means poor prognosis and high mortality ${ }^{5}$. The CURB-65 is based on the CURB parameters: confusion, urea, respiration rate, and blood pressure. A score of 1 is given to each parameter for patients aged 65 or over ${ }^{6,7}$. Thus both scoring systems use patient's age as an important parameter. However, these systems are not effective to assess patients with a high mortality risk as much as it is for measuring patients with a low mortality risk ${ }^{8,9}$.

In addition to PSI and CURB-65, biological markers have been developed to predict the severity of pneumonia in patients during the early infection. Among them, procalcitonin, a calcitonin precursor, has been reported as an useful indicator in assessment of severity of pneumonia $^{10,11}$. The use of procalcitonin was more evident for bacterial infections, including sepsis than local and viral infection as it facilitates not only assessment of severity but also identification of associated bacteria ${ }^{12,13}$. Procalcitonin can also help reduce unwanted antibiotic treatment when its change is closely monitored ${ }^{14}$. Study results on the association between PSI and procalcitonin have been divided. But Masia et al. ${ }^{15}$ claimed high levels of procalcitonin and subsequent increase in incidence of complications and mortality in the group with high PSI scores. Given a rapid increase in serum density during the early infection, procalcitonin tests allow easy specimen sampling, simple testing and prompt results. It is therefore very useful for older people as their symptoms may not be prominent and an invasive testing is not appropriate for them.

This study was aimed to evaluate the effectiveness of procalcitonin as a screening tool in assessing the severity and mortality risk in community-acquired pneumonia in elderly people.

\section{Materials and Methods}

\section{Study subjects}

A total of 250 patients admitted to Busan University Hospital due to community-acquired pneumonia and underwent the procalcitonin test during the period from January through December 2009. Their medical records were retrospectively analyzed. A total of 95 patients who developed pneumonia in 48 hours after initial hospital admission or received the procalcitonin test after taking antibiotics were excluded. The remaining 155 subjects were grouped into two groups using age 65 as a cutoff. And the differences in CURB-65, PSI, white blood cell, C-reactive protein (CRP), and procalcitonin test results were compared.

\section{Study methods}

Age, gender, comorbidities, white blood cell at admission, CRP, procalcitonin, length of hospital stay, and mortality. Charlson's comorbidity index (CCI ${ }^{16}$ were calculated based on comorbidities. PSI levels and CURB-65 were calculated to estimate the severity of pneumonia. PSI class $\geq I V$ and CURB-65 score $\geq 2$ are defined as severe pneumonia. Sputum samples were incubated and evaluated to detect pathogenic bacteria of pneumonia. Serum samples were tested to evaluate the role of Mycoplasma pneumonia and Chlamydia pneumonia. Also, urinary antigen test was performed and nasopharyngeal smear examined to detect Streptococcus pneumonia and influenza virus.

Community-acquired pneumonia is defined as the presence of respiratory symptoms including a fever of $38^{\circ} \mathrm{C}$, purulent sputum, cough, shortness of breath, backed by signs of new pulmonary infiltration on the radiograph. CURB-65 was measured on a six point scale (range, 0-5) by adding a score of 1 for each of the following conditions: decreased consciousness, blood urea nitrogen $>20 \mathrm{mg} / \mathrm{dL}$, respiration rate of more than 30 times, systolic blood pressure of less than $90 \mathrm{~mm} \mathrm{Hg}$, diastolic blood pressure $60 \mathrm{~mm} \mathrm{Hg}$ or less. PSI score was calculated, and each score places a patient into one of four risk classes (range, I-IV). Procalcitonin level was 
measured using an enzyme linked fluorescent assay (VIDAS BRAHMS procalcitonin; bioMérieux SA, Marcyl'Etoile, France). Based on out-of-hospital mortality, patients were divided into a survival and a death group. Hopeless state was classified as death.

\section{Statistical analysis}

Statistical analysis was performed using SPSS version 18.0 (SPSS Inc., Chicago, IL, USA). Pearson chi-square test or Fisher's exact test was performed for univariate comparison of discrete variables. Student t-test was used to compare continuous variables, including age, CCI, length of hospital staym procalcitonin and PSI. Results are expressed as mean \pm standard deviation. Spearman correlation and receiver operating characteristic (ROC) curve analysis was performed to evaluate biomarkers for risk prediction of pneumonia severity. Lastly, a logistic regression was used to estimate the effects of the cut-off value of procalcitonin on risks of pneumonia and mortality. Data results with $\mathrm{p}$-values of less than 0.05 are considered statistically significant.

\section{Results}

\section{Clinical characteristics of subjects}

The average age was $52.3 \pm 10.4$ years and $74.5 \pm 6.6$ years, respectively in the under-65 age group and the $65+$ age group. Charlson's comorbidity score was high-

Table 1. Clinical characteristics of total enrolled patients

\begin{tabular}{lccc}
\hline & 265 years $(\mathrm{n}=99)$ & $<65$ years $(\mathrm{n}=56)$ & $\mathrm{p}$-value \\
\hline Mean age, yr & $74.51 \pm 6.64$ & $52.34 \pm 10.44$ & $<0.001$ \\
Range of age, yr & $65-98$ & $19-64$ & - \\
Male gender & $74(74.7)$ & $25(44.6)$ & 0.653 \\
Charlson's comorbidty score & $2.828 \pm 2.62$ & $2.393 \pm 2.83$ & 0.336 \\
Hospital LOS, days & $14.96 \pm 13.24$ & $16.70 \pm 17.20$ & 0.483 \\
Hospital mortality & $19(19.2)$ & $7(12.5)$ & 0.463 \\
WBC, 10 ${ }^{3} / \mu \mathrm{L}$ & $13,620 \pm 7,056$ & $12,367 \pm 6,191$ & 0.269 \\
CRP, mg/dL & $14.81 \pm 11.05$ & $14.54 \pm 11.74$ & 0.888 \\
Procalcitonin, ng/mL & $4.80 \pm 14.54$ & $3.16 \pm 8.65$ & 0.444 \\
PSI score & $104.25 \pm 29.02$ & $74.39 \pm 30.52$ & $<0.001$ \\
Class I & $0(0)$ & $5(8.9)$ & $<0.001$ \\
Class II & $14(14.1)$ & $24(42.9)$ & - \\
Class III & $21(21.2)$ & $14(25)$ & - \\
Class IV & $51(51.5)$ & $9(16.1)$ & - \\
Class V & $13(13.1)$ & $4(7.1)$ & - \\
CURB-65 & $1.44 \pm 0.66$ & $0.21 \pm 0.46$ & $<0.001$ \\
0 & $0(0)$ & $45(80.4)$ & $<0.001$ \\
1 & $63(63.6)$ & $10(17.9)$ & - \\
2 & $29(29.3)$ & $1(1.8)$ & - \\
3 & $6(6.1)$ & $0(0)$ & - \\
4 & $1(1.0)$ & $0(0)$ & - \\
Microbiology & $9(9.0)$ & $5(8.9)$ & 0.973 \\
Streptococcus pneumonia & $4(4.0)$ & $1(1.8)$ & 0.654 \\
Klebsiella pneumonia & $4(4.0)$ & $5(8.9)$ & 0.285 \\
Staphylococcus aureus & $8(8.1)$ & $10(17.9)$ & 0.068 \\
Mycoplasma pneumonia & $7(7.1)$ & $3(5.4)$ & 1.0 \\
Chlamydia pneumonia & $4(4.0)$ & $2(3.6)$ & 1.0 \\
Influenza virus & & & \\
\hline
\end{tabular}

Values are presented as number of patients (\%) or means \pm standard deviation.

LOS: length of stay; WBC: white blood cell; CRP: C-reactive protein; PSI: pneumonia severity index. 
$\mathrm{JH}$ Kim et al: Procalcitonin as a predictor of severe pneumonia in the elderly

er in the $65+$ age group, compared with the under- 65 age group (2.82 \pm 2.62 vs. $2.39 \pm 2.83$ ), although the difference was not significant. Length of hospital stay was $16.7 \pm 17.2$ days and $14.9 \pm 13.2$ days, respectively, in the under-65 age group and the $65+$ age group.

The mean PSI score was $104.25 \pm 29.02$ in the $65+$ age group. Patients with risk class IV constituted the largest group (51.5\%), followed by the class III group (21.2\%), the class II group (14.1\%), and the class $\mathrm{V}$ group (13.1\%). The mean CURB-65 score was $1.44 \pm$ 0.66 in the same group in which $63.6 \%$ of patients had a score of 1 , followed by score 2 (29.3\%), score 3 (6.1\%), and score $4(1.0 \%)$. The mean PSI score was $74.39 \pm 29.02$ in the under-65 age group. Patients with risk class II constituted the largest group (42.9\%), followed by the class III group (25\%) and the class IV group (16.1\%). The mean CURB-65 score was 0.21土 0.46 in the same group in which $80.4 \%$ of patients had a score of 0 , followed by score 1 (17.9\%) and score $2(1.8 \%)$. Higher levels of white blood cells, CRP and procalcitonin were observed in the $65+$ age group, compared with the younger age group $(13,620 / \mu \mathrm{L}$ vs. $12,367 / \mu \mathrm{L}, 14.81 \mathrm{mg} / \mathrm{dL}$ vs. $14.54 \mathrm{mg} / \mathrm{dL}$, and 4.80 $\mathrm{ng} / \mathrm{mL}$ vs. $3.16 \mathrm{ng} / \mathrm{mL}$, respectively). However, the differences in these inflammatory markers were not significant.

S. pneumonia (9\%) was the most common cause of bacterial pneumonia in the $65+$ age group while $M$. pneumonia (17.9\%) was in the under-65 age group (Table 1).

\section{The association between pneumonia severity and inflammatory indicators}

Correlation analysis was used to estimate the relationship between white blood cell count, CRP and procalcitonin and CURB-65 score, PSI class and length of hospital stay. A significantly positive correlation was observed between procalcitonin level and CURB-65 ( $\rho=$ $0.309, \mathrm{p}=0.01)$ and PSI $(\rho=0.306, \mathrm{p}=0.01)$ in all age groups. This significantly positive relationship was also found in the $65+$ age group with CURB- 65 ( $\rho=0.408$, $\mathrm{p}=0.01)$ and PSI $(\rho=0.263, \mathrm{p}=0.01)$. However, no asso- ciation was present between procalcitonin level and length of hospital stay. The other two inflammatory indicators, CRP and white blood cell count were not associated with pneumonia severity in all age groups. However, white blood cells were positively correlated with CURB-65 scores in the $65+$ age group (Table 2).

Based on a positive correlation between procalcitonin, white blood cells and PSI, CURB-65, ROC curve analysis was performed. When PSI class of IV or above was defined as severe community-acquired pneumonia, area under the ROC curve (AUC) was 0.663 for procalcitonin (Figure 1). With the cutoff value of 2 in CURB-65, AUC increased to 0.741 for procalcitonin while AUC was 0.644 for white blood cell count. Thus procalcitonin level demonstrated more effectively to predict pneumonia severity, compared with white blood cell count. A cutoff value of $0.265 \mathrm{ng} / \mathrm{mL}$ showed a sensitivity of $88.9 \%$ and specificity of $52.4 \%$ for procalcitonin (Figure 2).

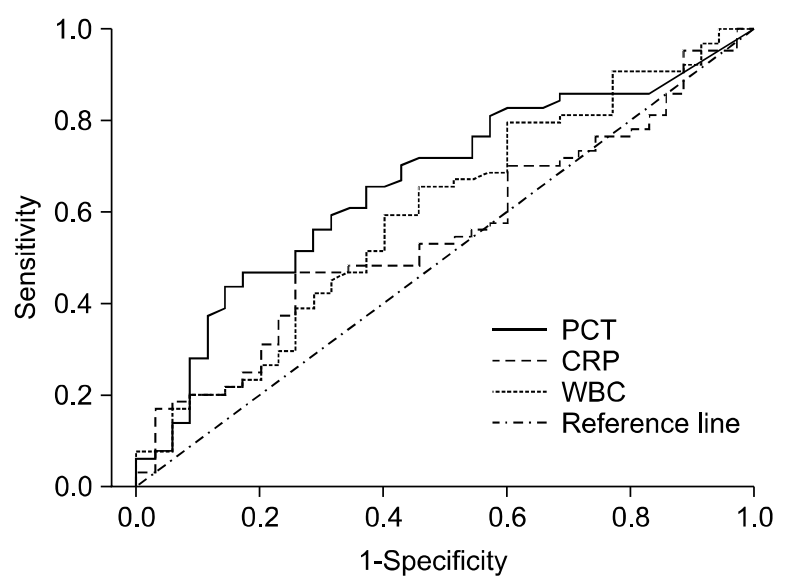

Figure 1. Receiver operating characteristic curves of procalcitonin (AUC 0.663), CRP (AUC 0.556), WBC (AUC 0.597 ) for prediction of severe community-acquired pneumonia defined as $\mathrm{PSI} \geq \mathrm{IV}$ in the elderly CAP patients ( $\geq$ 65 years). AUC: area under the curve; CRP: C-reactive protein; WBC: white blood cell; PSI: pneumonia severity index; CAP: community-acquired pneumonia; PCT: procalcitonin. 


\section{Correlation between procalcitonin levels and seve-} rity and morality risk in community-acquired pneumonia

Logistic regression was performed to determine the correlation between procalcitonin levels and severity and morality risk in patients with community-acquired pneumonia. In all age groups, the odds ratio for severe pneumonia showed a seven- to eight-hold increase for PSI and CURB-65 at procalcitonin level of $2.0 \mathrm{ng} / \mathrm{mL}$ or higher. However, the odd ratio remained unchanged with procalcitonin levels of higher than 10 $\mathrm{g} / \mathrm{mL}$. The odd ratio for mortality had a seven-fold in-

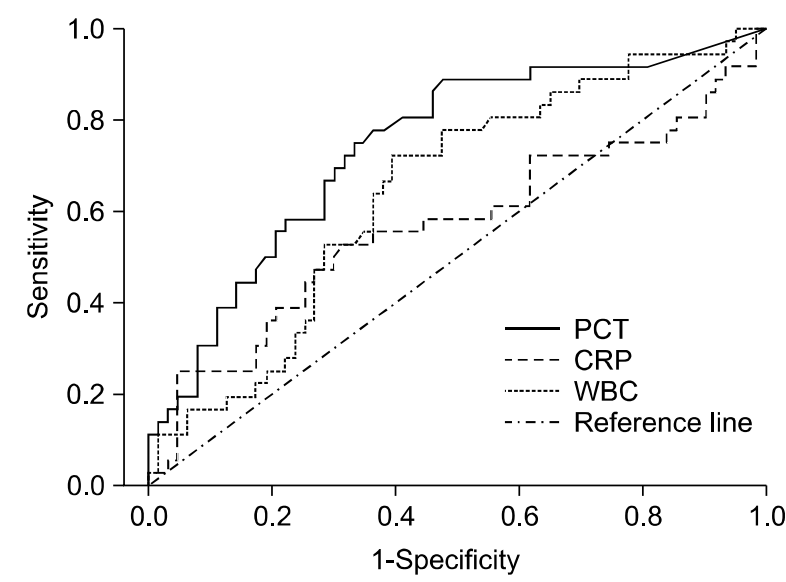

Figure 2. Receiver operating characteristic curves comparing procalcitonin (AUC 0.741), CRP (AUC 0.567), WBC (AUC 0.644) for prediction of severe community-acquired pneumonia defined as CURB-65 $\geq \|$ in the elderly CAP patients ( $\geq 65$ years). AUC: area under the curve; CRP: C-reactive protein; WBC: white blood cell; CAP: community-acquired pneumonia; PCT: procalcitonin. crease with procalcitonin levels of higher than 10 $\mathrm{ng} / \mathrm{mL}$ (Table 3). In the $65+$ age group, the odds ratio was positively correlated with procalcitonin levels showing a 5-fold, 7.1-fold, and 8.7-fold increase, respectively, with procalcitonin level of $0.5 \mathrm{ng} / \mathrm{mL}, 2.0$ $\mathrm{ng} / \mathrm{mL}$, and $10 \mathrm{ng} / \mathrm{mL}$ or above. However, no correlation was found between procalcitonin levels and mortality in this group (Table 4).

\section{Discussion}

Calcitonin is a hormone released from C-cells of the thyroid gland with the function of regulating the body's calcium metabolism. However, its precursor, procalcitonin has almost no hormonal activity ${ }^{17}$. Microbial infection induces increases of calcitonin gene expression via endotoxin or pro-inflammatory cytokines and a constitutive release of procalcitonin from all parenchymal

Table 2. Correlation of biomarkers and CURB-65, PSI, hospitalization periods in subjects

\begin{tabular}{lllll}
\hline & & \multicolumn{3}{c}{ Correlation coefficient $(\rho)$} \\
\cline { 3 - 5 } & & Procalcitonin & CRP & WBC \\
\hline All age & CURB-65 & $0.309^{\star \star}$ & 0.110 & 0.144 \\
& PSI & $0.306^{\star *}$ & 0.115 & 0.136 \\
& Hospital LOS & 0.120 & 0.064 & 0.123 \\
\multirow{5}{*}{$\geq 65$ years } & CURB-65 & $0.408^{\star \star}$ & 0.108 & $0.226^{\star}$ \\
& PSI & $0.263^{\star \star}$ & 0.107 & 0.188 \\
& Hospital LOS & 0.054 & 0.076 & 0.148 \\
\hline
\end{tabular}

*Spearman correlation is significant at the 0.05 level (2-tailed). ${ }^{*}$ Spearman correlation is significant at the 0.01 level (2-tailed). CRP: C-reactive protein; WBC: white blood cell; PSI: pneumonia severity index; LOS: length of stay.

Table 3. Logistic regression result for predicting severe pneumonia: all patients

\begin{tabular}{|c|c|c|c|c|c|c|c|}
\hline \multirow{2}{*}{$\begin{array}{l}\text { Procalcitonin } \\
\text { (ng/mL) }\end{array}$} & \multirow{2}{*}{ No. (\%) } & \multicolumn{2}{|c|}{$\mathrm{PSI} \geq \mathrm{IV}$} & \multicolumn{2}{|c|}{ CURB-65 $\geq 2$} & \multicolumn{2}{|c|}{ Mortality } \\
\hline & & OR & $95 \% \mathrm{Cl}$ & OR & $95 \% \mathrm{Cl}$ & OR & $95 \% \mathrm{Cl}$ \\
\hline$<0.05$ & $23(12.4)$ & 1.0 & - & 1.0 & - & 1.0 & - \\
\hline $0.05-0.49$ & $65(34.9)$ & 0.91 & $0.34-2.42$ & 0.68 & $0.16-2.97$ & 0.57 & $0.12-2.58$ \\
\hline $0.5-1.99$ & $31(16.7)$ & 1.28 & $0.43-3.83$ & 3.18 & $0.76-13.24$ & 1.67 & $0.37-7.53$ \\
\hline $2.00-9.99$ & $18(9.7)$ & 7.78 & $1.74-34.72$ & 8.33 & $1.81-38.43$ & 2.05 & $0.39-10.70$ \\
\hline$\geq 10$ & $18(9.7)$ & 7.78 & $1.74-34.72$ & 5.33 & $1.15-24.60$ & 7.61 & $1.57-37.05$ \\
\hline
\end{tabular}

PSI: pneumonia severity index; OR: odds ratio; Cl: confidence interval. 
$\mathrm{JH} \mathrm{Kim} \mathrm{et} \mathrm{al:} \mathrm{Procalcitonin} \mathrm{as} \mathrm{a} \mathrm{predictor} \mathrm{of} \mathrm{severe} \mathrm{pneumonia} \mathrm{in} \mathrm{the} \mathrm{elderly}$

Table 4. Logistic regression result for predicting severe pneumonia: $\geq 65$ years

\begin{tabular}{|c|c|c|c|c|c|c|c|}
\hline \multirow{2}{*}{$\begin{array}{l}\text { Procalcitonin } \\
\qquad(\mathrm{ng} / \mathrm{mL})\end{array}$} & \multirow{2}{*}{ No. (\%) } & \multicolumn{2}{|c|}{$\mathrm{PSI} \geq \mathrm{IV}$} & \multicolumn{2}{|c|}{ CURB-65 $\geq 2$} & \multicolumn{2}{|c|}{ Mortality } \\
\hline & & OR & $95 \% \mathrm{Cl}$ & OR & $95 \% \mathrm{Cl}$ & OR & $95 \% \mathrm{Cl}$ \\
\hline$<0.05$ & $18(18.2)$ & 1.0 & - & 1.0 & - & 1.0 & - \\
\hline $0.05-0.49$ & $33(33.3)$ & 1.11 & $0.24-5.09$ & 1.2 & $0.38-3.79$ & 0.52 & $0.09-2.88$ \\
\hline $0.5-1.99$ & $20(20.2)$ & 5.0 & 1.09-22.82 & 1.86 & $0.50-6.83$ & 1.67 & $0.34-8.26$ \\
\hline $2.00-9.99$ & $17(17.2)$ & 7.14 & $1.48-34.38$ & 7.50 & $1.32-42.76$ & 1.15 & $0.20-6.73$ \\
\hline$\geq 10$ & $11(11.1)$ & 8.75 & $1.53-50.11$ & 4.50 & $0.75-26.93$ & 5.0 & $0.87-28.86$ \\
\hline
\end{tabular}

PSI: pneumonia severity index; OR: odds ratio; Cl: confidence interval.

tissues of the body. Bypassing enzymatic degradation to calcitonin makes the level of procalcitonin in the blood to be maintained high ${ }^{18}$. Procalcitonin reaches its peak within 2-4 hours after bacteria or endotoxin stimulation, making an early screening for infection possible and providing a rationale for administration of antibiotics even before the results of cultural methods are ready ${ }^{19}$. Besides, procalcitonin testing is performed with serum samples, making it more suitable for elderly people than microorganism tests. In the presence of sepsis or septic shock, procalcitonin release is accelerated, making it effective for evaluating the severity of inflammation $^{20}$. The half life of serum procalcitonin is $20-$ 24 hours. As it is a long enough to measure procalcitonin after initial administration of antibiotics, the duration of unwanted antibiotics treatment could be reduced ${ }^{14}$.

Procalcitonin has proven effective for assessing pneumonia severity and predicting mortality risk in community-acquired pneumonia. Procalcitonin levels were determined by enzyme-linked fluorescent assay. The cutoff value of lower than $0.05 \mathrm{ng} / \mathrm{mL}$ for procalcitonin indicates low risk of infection. Procalcitonin level of 0.05 $\mathrm{ng} / \mathrm{mL}$ or higher indicates local infection whereas the levels of higher than $0.5 \mathrm{ng} / \mathrm{mL}, 2 \mathrm{ng} / \mathrm{mL}$, and $10 \mathrm{ng} / \mathrm{mL}$ are described as a sepsis, severe sepsis and septic shock, respectively ${ }^{21}$. In this study, procalcitonin levels were associated with PSI and CURB-65. AUC was 0.663 for procalcitonin with PSI class of IV or above and 0.741 with CURB-65 score of 2 or higher when both criteria was defined as severe community-acquired pneumonia, Procalcitonin assessment was more useful than CRP and white blood cell count.
However, researchers are divided in their opinion of the effectiveness of procalcitonin among biological markers. Simon et al. ${ }^{22}$ claimed procalcitonin is more accurate than CRP as a diagnostic indicator of bacterial infection. Bafadhel et al. ${ }^{23}$ asserted CRP is more effective than procalcitonin in term of AUC in assessing community-acquired pneumonia. Serum CRP has been found to rise in patients with chronic inflammatory diseases, including cardiovascular disease, metabolic syndrome and colorectal cancer ${ }^{24}$. Also, older people are at a high risk of comorbidities, meaning that their baseline CRP levels tend to be high in many incidences. This tendency supports the finding of this study that CRP was less effective than procalcitonin for predicting severity of pneumonia in elderly people. Still, the increase in CRP level is weakened by suppressive agents such as steroids. While CRP level is affected by various conditions, procalcitonin remains useful as diagnostic tool ${ }^{25}$. A higher effectiveness of procalcitonin in diagnosing pneumonia and assessing severity has been therefore more prominent. Procalcitonin proved to be most effective among markers of sepsis in a study ${ }^{26}$. In this study, procalcitonin outperformed CRP in evaluating severity of pneumonia. This result is supported by earlier studies because severe pneumonia easily exacerbates sepsis or severe sepsis in older people. This finding reinforces the idea that procalcitonin level is highly effective as a single predictor of prognosis in severe pneumonia. In addition, it is said that CURB-65 and PSI levels are not effective to screen patients with high risk of severe pneumonia as much as it is for screening those with low risk. 
Procalcitonin is also known to be reliable method of predicting mortality rate, compared with CRP and white blood cell count ${ }^{27}$. Kruger et al. ${ }^{28}$ suggested the cutoff value of $0.228 \mathrm{ng} / \mathrm{mL}$ for mortality of community-acquired pneumonia. Meng et al. ${ }^{29}$ proposed $10 \mathrm{ng} / \mathrm{mL}$ as the criterion for short-term mortality in intensive care patients. The $10 \mathrm{ng} / \mathrm{mL}$ cutoff value for mortality risk in all age groups was higher than that reported in previous studies. A higher cutoff value was attributable to a high proportion of intensive care patients in our hospital, one of the largest hospitals in Busan. However, there was no significant relationship between procalcitonin and mortality of pneumonia in the elders. That can be simply explained by high risk of comorbidities. This means that pneumonia can be further exacerbated by complications of concurrent disease. Although baseline procalcitonin level was lower than the cutoff value for mortality risk, mortality in older adults with pneumonia is caused by other conditions than pneumonia in many incidences. In that case, mortality is explained by procalcitonin despite its prognostic value.

This study has limitations to reveal the cause and effect relationship between pneumonia and mortality through retrospective analysis. At the same time, baseline procalcitonin levels may not be correct to reflect the early infection if some patients began taking antibiotics before being admitted to our hospital and medical records did not contain such information. In addition, variables that can improve procalcitonin were not controlled in this study. The variables included bacteremia, systemic inflammatory response, multiple organ dysfunction syndrome and creatinine clearance. Another limitation includes uncontrolled administration of antibiotics for the group who needed discrete use of antibiotics due to a high procalcitonin level at baseline and old age. Uncontrolled antibiotics use between groups may serve as a potential confounding factor ${ }^{30}$.

Biological indicators associated with immune system is slowed during aging process, procalcitonin tests demonstrated a low sensitivity and predicting performance in screening infections in elderly people. However, procalcitonin proved its effectiveness in predicting pneu- monia severity in elderly people while diagnosis and prognosis prediction pose a difficulty for them due to atypical symptoms and involved invasive testing. Although mortality risk was not correlated with changes in the cutoff values, choosing a new cutoff value for more accurate diagnosis and prognosis prediction is necessary to overcome the effects of aging process on procalcitonin responses. At the same time, a large scale of prospective study is also needed.

\section{Acknowledgements}

This work was supported by a 2-year research grant of Pusan National University.

\section{References}

1. Korea National Statistical Office. 2011 Annual report on the cause of death statistics. Daejeon: Korea National Statistical Office; 2011.

2. Loeb M. Pneumonia in older persons. Clin Infect Dis 2003;37:1335-9.

3. Johnson JC, Jayadevappa R, Baccash PD, Taylor L. Nonspecific presentation of pneumonia in hospitalized older people: age effect or dementia? J Am Geriatr Soc 2000;48:1316-20.

4. Mandell LA, Wunderink RG, Anzueto A, Bartlett JG, Campbell GD, Dean NC, et al. Infectious Diseases Society of America/American Thoracic Society consensus guidelines on the management of community-acquired pneumonia in adults. Clin Infect Dis 2007; 44 Suppl 2:S27-72.

5. Fine MJ, Auble TE, Yealy DM, Hanusa BH, Weissfeld LA, Singer DE, et al. A prediction rule to identify low-risk patients with community-acquired pneumonia. N Engl J Med 1997;336:243-50.

6. Neill AM, Martin IR, Weir R, Anderson R, Chereshsky A, Epton MJ, et al. Community acquired pneumonia: aetiology and usefulness of severity criteria on admission. Thorax 1996;51:1010-6.

7. Lim WS, van der Eerden MM, Laing R, Boersma WG, Karalus N, Town GI, et al. Defining community acquired pneumonia severity on presentation to hospital: an international derivation and validation study. Thorax 2003;58:377-82.

8. American College of Emergency Physicians. Clinical policy for the management and risk stratification of 
community-acquired pneumonia in adults in the emergency department. Ann Emerg Med 2001;38:107-13.

9. Yealy DM, Auble TE, Stone RA, Lave JR, Meehan TP, Graff LG, et al. Effect of increasing the intensity of implementing pneumonia guidelines: a randomized, controlled trial. Ann Intern Med 2005;143:881-94.

10. Hedlund J, Hansson LO. Procalcitonin and C-reactive protein levels in community-acquired pneumonia: correlation with etiology and prognosis. Infection 2000;28: $68-73$.

11. Hausfater P, Garric S, Ayed SB, Rosenheim M, Bernard $\mathrm{M}$, Riou B. Usefulness of procalcitonin as a marker of systemic infection in emergency department patients: a prospective study. Clin Infect Dis 2002;34:895-901.

12. Assicot M, Gendrel D, Carsin H, Raymond J, Guilbaud J, Bohuon C. High serum procalcitonin concentrations in patients with sepsis and infection. Lancet 1993;341: 515-8.

13. Ahn S, Kim WY, Yoon JY, Sohn CH, Seo DW, Kim $\mathrm{SH}$, et al. Procalcitonin in $2009 \mathrm{H} 1 \mathrm{N1}$ influenza pneumonia: role in differentiating from bacterial pneumonia. Tuberc Respir Dis 2010;68:205-11.

14. Christ-Crain M, Stolz D, Bingisser R, Muller C, Miedinger D, Huber PR, et al. Procalcitonin guidance of antibiotic therapy in community-acquired pneumonia: a randomized trial. Am J Respir Crit Care Med 2006;174:84-93.

15. Masia M, Gutierrez F, Shum C, Padilla S, Navarro JC, Flores $\mathrm{E}$, et al. Usefulness of procalcitonin levels in community-acquired pneumonia according to the patients outcome research team pneumonia severity index. Chest 2005;128:2223-9.

16. Charlson ME, Pompei P, Ales KL, MacKenzie CR. A new method of classifying prognostic comorbidity in longitudinal studies: development and validation. J Chronic Dis 1987;40:373-83.

17. Le Moullec JM, Jullienne A, Chenais J, Lasmoles F, Guliana JM, Milhaud G, et al. The complete sequence of human preprocalcitonin. FEBS Lett 1984;167:93-7.

18. Christ-Crain M, Muller B. Biomarkers in respiratory tract infections: diagnostic guides to antibiotic prescription, prognostic markers and mediators. Eur Respir J 2007; 30:556-73.

19. Karzai W, Oberhoffer M, Meier-Hellmann A, Reinhart K. Procalcitonin: a new indicator of the systemic re- sponse to severe infections. Infection 1997;25:329-34.

20. Muller B, Harbarth S, Stolz D, Bingisser R, Mueller C, Leuppi J, et al. Diagnostic and prognostic accuracy of clinical and laboratory parameters in community-acquired pneumonia. BMC Infect Dis 2007;7:10.

21. Christ-Crain M, Muller B. Procalcitonin in bacterial infections: hype, hope, more or less? Swiss Med Wkly 2005;135:451-60.

22. Simon L, Gauvin F, Amre DK, Saint-Louis P, Lacroix J. Serum procalcitonin and C-reactive protein levels as markers of bacterial infection: a systematic review and meta-analysis. Clin Infect Dis 2004;39:206-17.

23. Bafadhel M, Clark TW, Reid C, Medina MJ, Batham S, Barer MR, et al. Procalcitonin and C-reactive protein in hospitalized adult patients with community-acquired pneumonia or exacerbation of asthma or COPD. Chest 2011;139:1410-8.

24. Black S, Kushner I, Samols D. C-reactive protein. J Biol Chem 2004;279:48487-90.

25. Muller B, Peri G, Doni A, Perruchoud AP, Landmann R, Pasqualini F, et al. High circulating levels of the IL-1 type II decoy receptor in critically ill patients with sepsis: association of high decoy receptor levels with glucocorticoid administration. J Leukoc Biol 2002;72:643-9.

26. American College of Chest Physicians/Society of Critical Care Medicine Consensus Conference: definitions for sepsis and organ failure and guidelines for the use of innovative therapies in sepsis. Crit Care Med 1992;20: 864-74.

27. Jensen JU, Heslet L, Jensen TH, Espersen K, Steffensen $\mathrm{P}$, Tvede M. Procalcitonin increase in early identification of critically ill patients at high risk of mortality. Crit Care Med 2006;34:2596-602.

28. Kruger S, Ewig S, Marre R, Papassotiriou J, Richter K, von Baum $\mathrm{H}$, et al. Procalcitonin predicts patients at low risk of death from community-acquired pneumonia across all CRB-65 classes. Eur Respir J 2008;31:349-55.

29. Meng FS, Su L, Tang YQ, Wen Q, Liu YS, Liu ZF. Serum procalcitonin at the time of admission to the ICU as a predictor of short-term mortality. Clin Biochem 2009; 42:1025-31.

30. Stucker F, Herrmann F, Graf JD, Michel JP, Krause KH, Gavazzi G. Procalcitonin and infection in elderly patients. J Am Geriatr Soc 2005;53:1392-5. 